\title{
ANTI-COLLAPSE ANALYSIS OF UNEQUAL SPAN STEEL BEAM-COLUMN SUBSTRUCTURE CONSIDERING THE COMPOSITE EFFECT OF FLOOR SLABS
}

\author{
Wei-hui Zhong ${ }^{1,2,{ }^{*}}$, Zheng Tan ${ }^{1}$, Xiao-yan Song ${ }^{1}$ and Bao Meng ${ }^{1}$ \\ ${ }^{1}$ School of Civil Engineering, Xi'an University of Architecture \& Technology, Xi'an 710055, China \\ ${ }^{2}$ Key Lab of Structural Engineering and Earthquake Resistance, Ministry of Education, Xi'an University of Architecture and Technology, Xi'an 710055 , China \\ *(Corresponding author: E-mail:zhongweihui1980@163.com)
}

\section{A B S T R A C T}

Based on the alternate load path method and considering the composite effect of floor slabs, a beam-column frame with unequal spans was studied to derive the equations for the load-deformation relationship at five different stages (elastic, elastic-plastic, plastic, transient, and catenary) during progressive collapse. The anti-collapse mechanism of the composite beam-column frame and the influence of arch action were carefully analyzed. A numerical model was established using ABAQUS for the relevant model, and the model was verified by comparison with experimental data. Further, the theoretical equations were compared with the results of numerical simulations for different span ratios. The results show that the theoretical equations possess good generality and high accuracy for analyzing progressive collapse of a composite beam-column frame with unequal spans.
ART ICLE HISTORY

$\begin{array}{ll}\text { Received: } & \text { 25 December } 2018 \\ \text { Revised: } & \text { 05 August } 2019 \\ \text { Accepted: } & \text { 11 August } 2019\end{array}$

\section{K E Y W O R D S}

Composite beam-column frame; Anti-collapse mechanism; Progressive collapse; Arch action;

Unequal spans

Copyright (๑) 2019 by The Hong Kong Institute of Steel Construction. All rights reserved.

\section{Introduction}

A fundamental aim of structural design is to ensure the safety of a structure; specifically, to prevent progressive collapse of the structure. Once progressive collapse occurs, it is often catastrophic and can cause serious loss of life and property. Therefore, methods to prevent the progressive collapse of structures are an important part of the theoretical and experimental practice of structural engineering. When vertical load-bearing components (columns) in a structure are destroyed, the remaining structure will redistribute the internal forces. With increasing vertical deformation, the internal force in the horizontal members (beams) gradually changes from flexural to tensile to carry the vertical loads, forming what is called a catenary mechanism. At this stage, the catenary mechanism is the last line of defense against progressive collapse of the structure, and therefore, it is a key component in the anti-collapse design of a structure.

Research regarding anti-collapse mechanisms of beam-column frames currently focuses on pure steel frame beam-column structures with equal spans. Studies using unequal spans are rare, and the composite effect between supported concrete slabs and the steel beams is usually not considered. Demonceau and Jaspart ${ }^{[1]}$ conducted static loading tests on a single-story frame and proposed a mechanical model of the substructure considering the composite beam effect in different stages, where the load-displacement formula was deduced and verified. Izzuddin et al. ${ }^{[2-4]}$, Arash and Fereidoon ${ }^{[5]}$, and Vlassis et al ${ }^{[6]}$ theoretically analyzed the behavioral changes of steel beams with equal spans during the failure of the middle column, and proposed formulas for the anti-collapse bearing capacity. Li et al.$^{[7,8]}$ proposed a model of steel beams subjected to axial and rotational spring constraints under distributed loads. The constrained coefficient method and rigid plastic hinge model were used to derive the load-span deflection formula of constrained steel beams in different stages. The reliability of the formula was verified using finite element analysis. In our previous report [9], we analyzed the entire process of a beam-column substructure of a steel frame resisting external loads using the alternate load path method and deduced the formula for the anti-collapse bearing capacity and displacement of the beam-column substructure. The accuracy of the formula was verified using numerical examples.

Based on the alternate load path method ${ }^{[10]}$ and the constraint coefficient $\operatorname{method}^{[11]}$, a concrete slab and steel composite beam-column frame was considered in this study. The bearing capacity-deformation equations of the composite beam-column frame with unequal spans were derived for different stages of the process. The influence of arch action was also considered. A numerical analysis model was established using ABAQUS, and then validated by comparison with relevant test results. In addition, the results of the derived equations were compared with those of the numerical simulation for different span ratios. The results of the comparison indicate that the theoretical equations provide good versatility and high calculation accuracy for anti-collapse analysis of a composite beam-column frame with unequal spans.

\section{Analysis model of the composite beam-column substructure}

\subsection{Analysis model}

In the anti-collapse analysis of a frame structure, the floors above the failure column and the two spans connected to the failure column are usually defined as being in the direct influence area, while other parts are within the indirect influence area [3], as shown in Fig. 1. The direct influence area is the focus of anti-collapse research and design as it must directly bear the load resulting from the failure of the vertical load-bearing component in order to prevent progressive collapse, while the indirect influence area provides reliable boundary conditions for the direct influence area.

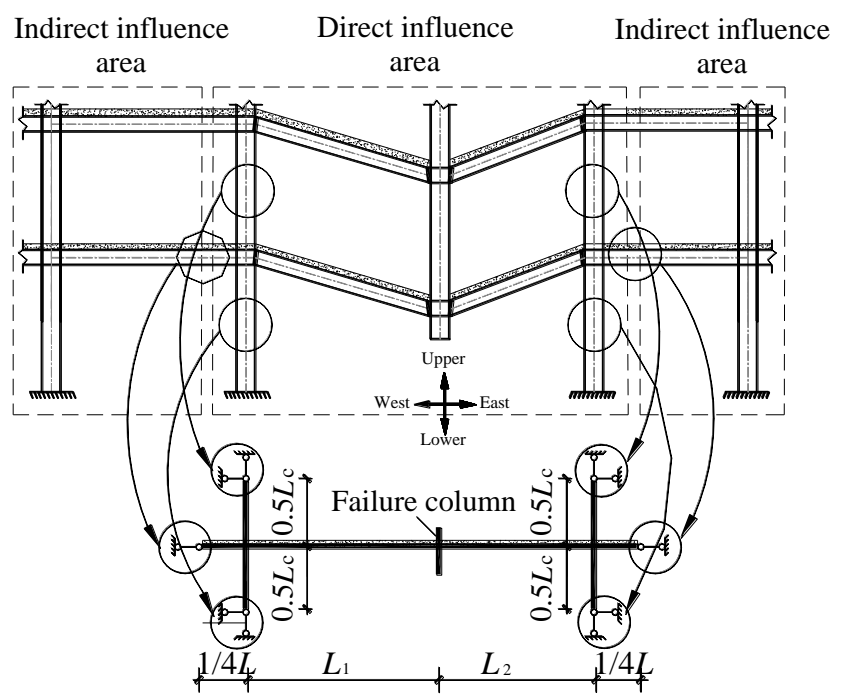

Fig. 1. Diagram defining the direct and indirect influence areas of the composite beam-column frame mode

The alternate load path method is currently the most commonly used method for analyzing and designing the collapse resistance of a frame structure. This method does not consider the cause of failure or the failure process of the column; it only considers the change in the behavior of the main components connected to the failure column under load. In the frame, the inflection point of the side column is approximately located in the middle of the story height. The quarter point $\left(L_{0}\right)$ of the beam in the panel adjacent to the failure column, between two intact column joints, is taken as the location of the boundary condition to simulate the constraint of the peripheral members. 
A composite frame model [12] consisting of two beams and three columns is shown in Fig. 1. When the middle column of this structure fails, the beams on each side of the column are subjected to an increasingly large deformation, and the resistance mechanism gradually transforms from beam action to catenary action.

As shown in Fig. 1, the joints of the composite beam-column frame model have both axial and rotational constraints. If the model is further simplified by applying an axially constrained spring and a rotationally constrained spring (corresponding to spring stiffnesses $K_{\mathrm{R}}$ and $K_{\mathrm{r}}$, respectively) at the joint, a simplified analysis model of the composite beam-column frame can be obtained, as shown in Fig. 2, in which the failure column allows only vertical movement and no rotation.

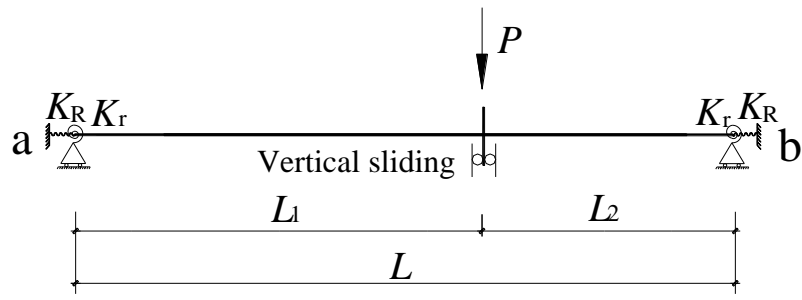

Fig. 2.Simplified analysis model of the composite beam-column frame direct influence area

\subsection{Analytical assumptions and response of a composite beam}

\subsubsection{Assumptions}

To obtain the bearing capacity-deformation equation of the composite beam-column frame, the following simplifications and assumptions were made:(1) The beam and column sections are all I-shaped sections, and the material is an ideal elastic-plastic material;(2) Rigid plastic hinges only appear on the beam;(3) The tensile strength of the concrete is negligible;(4) The slip between the steel beam and the concrete slab is not considered as the composite beam is assumed to contain a complete shear connection, while the differential deformation of the steel beam members and buckling of the flange plate are ignored.(5) The correlation between the axial force and bending moment of the composite beam section followed Eq. (1) [11,13]. (6) The joint has sufficient rotational deformation capability to allow the catenary effect to be fully developed and employed.

$\frac{M}{M_{\mathrm{p}}}+\frac{N}{N_{\mathrm{p}}}=1$

Here, $M_{\mathrm{p}}$ is the plastic limit bending moment of the composite beam section and $N_{\mathrm{p}}$ is the plastic limit axial force of the composite beam section.

\subsubsection{Response of composite beam under concentrated load}

A typical vertical bearing capacity (P) vs. deformation (V)curve (load-displacement curve) is used to describe the force in the joint and the tensilebending of the composite beam-column frame during progressive collapse, as shown in Fig. 3. Five clear stages are defined:the (1) elastic (OA), (2) elastic-plastic (AB), (3) plastic (BC), (4) transient (CD), and (5) catenary (DE) stages. The load-displacement curve in each stage is approximately linear.

In the elastic phase and the elastic-plastic phase (1) and (2), respectively in Fig. 3), the joint mainly relies on the bending moment of the section to resist the external force; the axial force is insignificant at this stage. The structure mainly resists collapse via the beam mechanism. The tensile-bending correlation curve mainly moves vertically from the origin to the plastic positive yielding moment $\mathrm{M}_{\mathrm{p}+}$ and to the plastic negative yielding moment $M_{\mathrm{p} \text { - }}$ of the composite beam, as shown in Fig. 4a. When the structure enters the plastic stage (3) in Fig. 3), the axial force is still insignificant. The joint reaches its plastic bending capacity and the load does not change over this defined range of displacement. In the tensile-bending correlation curve, the composite beam reaches the plastic bending yield moment $M_{\mathrm{p}+}$ at the mid-span and reaches the plastic negative yield bending moment $M_{\mathrm{p} \text { - }}$ at the beam end, as shown in Fig. 4b. When the plastic phase ends, the structure enters the transition stage (4) in Fig. 3 ), and significant axial force is generated in the composite beam. At this time, the composite beam-column structure begins to transform from being supported by the bending mechanism

to being supported by the catenary mechanism, and the axial force causes astate transformation of the joint. The tensile-bending correlation curve mainly moves linearly from the plastic yield bending moment to the plastic tensile bearing capacity, as shown in Fig. 4c. When the structure enters the catenary stage (5) in Fig. 3), the beam mechanism is no longer active; only axial tension exists in the composite beam, and the joint has yielded due to tensile stress, as shown in Fig. 4 d.

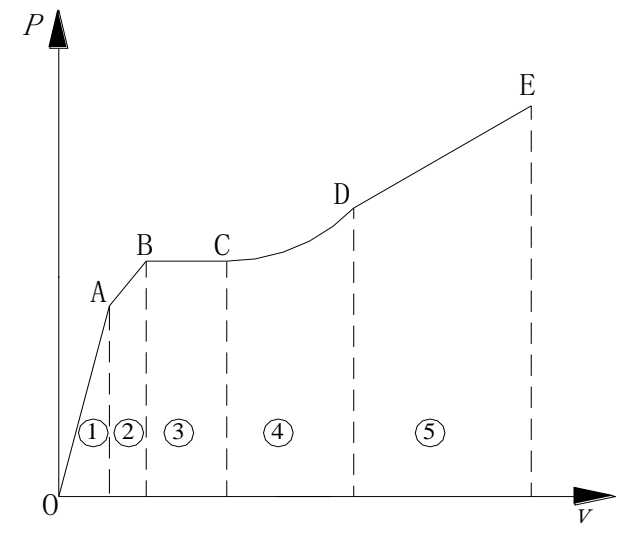

Fig. 3. Typical load-deformation curve for the composite beam-column substructure

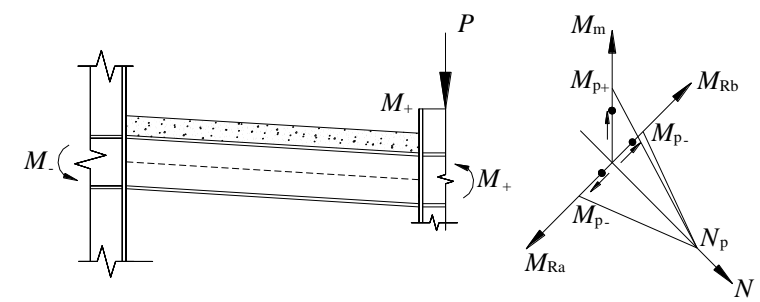

(a) Before joint yielding (elastic stage and elastic-plastic stage)

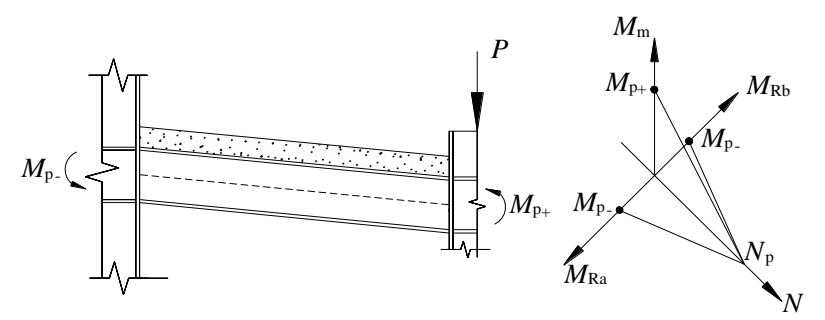

(b) Formation of plastic hinges (plastic stage)

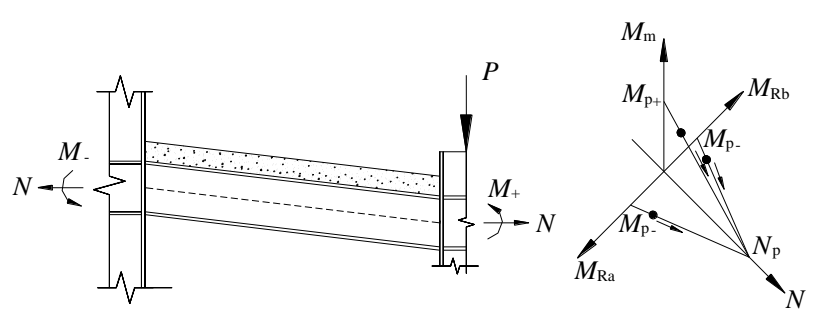

(c) Transformation from the beam mechanism to the catenary mechanism (transition stage)

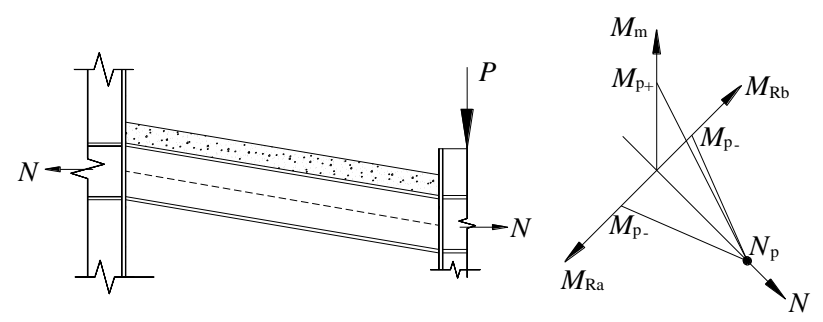

(d) Catenary mechanism (catenary stage)

Fig. 4. Behavior of the frame joints during different stages of progressive collapse

\section{Theoretical background of collapse stages}

Among the stages of progressive collapse of the composite beam-column frame defined in Fig. 3., the elastic-plastic stage reflects the process of forming plastic hinges at the end of the composite beam at the failure column and the side columns. This stage is a complex nonlinear process with too 
many influencing factors to accurately capture. To simplify the analysis, the behavior in this stage was approximated as a straight line. The various stages of the process are described here in detail.

\subsection{Elastic stage}

In the elastic stage, the beam-column frame mainly relies on the bending moment resistance of the section to resist the external force; as the axial force is ignored, only the action of the rotationally constrained spring is considered. The corresponding model of the elastic stage is shown in Fig. 5.

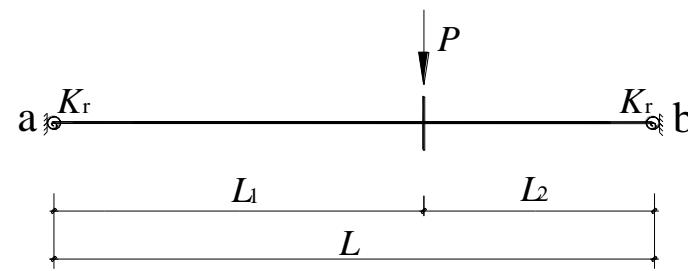

Fig. 5. Analysis model for the elastic stage

If ends $\mathrm{a}$ and $\mathrm{b}$ of the beam are considered to be hinged $\left(K_{\mathrm{r}}=0\right)$, then the bending moment $M_{\mathrm{sm}}$ at the beam end and vertical deformation $v_{\mathrm{s}}$ at the failure column are given by:

$M_{\mathrm{sm}}=\frac{P L_{1} L_{2}}{L}, \quad v_{\mathrm{s}}=\frac{P L_{1}^{2} L_{2}^{2}}{3 E I_{+} L}$

where, $E$ is the elastic modulus of the steel and $I_{+}$is the section moment of inertia of the composite beam, converted into steel under the positive bending moment [14]. If the beam ends a and b are fixed $\left(K_{\mathrm{r}} \rightarrow \infty\right)$, then the bending moment $M_{\mathrm{fm}}$ of the beam ends at the failure column, the vertical deformation $v_{\mathrm{f}}$ at the failure column, and the bending moments $M_{\mathrm{fa}}$ and $M_{\mathrm{fb}}$ of the beam ends at the side columns are given by:

$M_{\mathrm{fm}}=\frac{2 P L_{1}{ }^{2} L_{2}{ }^{2}}{L^{3}}, \quad v_{\mathrm{f}}=\frac{P L_{1}{ }^{3} L_{2}{ }^{3}}{3 E I_{+} L^{3}}$

$M_{\mathrm{fa}}=\frac{P L_{1} L_{2}^{2}}{L^{2}}, \quad M_{\mathrm{fb}}=\frac{P L_{1}^{2} L_{2}}{L^{2}}$

The actual state of the rotational constraint is a mixture of the hinged and fixed conditions. To simplify the analysis, the constraint coefficient method was adopted, introducing the rotational constraint coefficients $c_{\mathrm{f}}$ and $c_{\mathrm{s}}$ as follows:

$$
\begin{aligned}
& c_{\mathrm{f}}=\frac{K_{\mathrm{er}}}{K_{\mathrm{rm}}}=\frac{K_{\mathrm{rs}}}{2 K_{\mathrm{rm}}+K_{\mathrm{rs}}}, \quad c_{\mathrm{s}}=1-c_{\mathrm{f}}=\frac{2 K_{\mathrm{rm}}}{2 K_{\mathrm{rm}}+K_{\mathrm{rs}}} \\
& K_{\mathrm{er}}=\frac{1}{\frac{2}{K_{\mathrm{rs}}}+\frac{1}{K_{\mathrm{rm}}}}
\end{aligned}
$$

where $K_{\mathrm{er}}$ is the equivalent line stiffness of the composite beam; $K_{\mathrm{rs}}$ is the negative rotational stiffness of the composite beam corresponding to the negative bending moment; and $K_{\mathrm{rm}}$ is the positive rotational stiffness of the composite beam corresponding to the positive bending moment, as follows:

$$
K_{\mathrm{rm}}=\frac{E I_{+}}{L}, \quad K_{\mathrm{rs}}=\frac{E I_{-}}{L^{\prime}}
$$

where $I$. is the section moment of inertia of the composite beam converted into steel under the negative bending moment [14] and ${ }^{\prime}$ is the length of the rotational spring, calculated as follows [15]:

$L^{\prime}=L\left(\sqrt{\left(I_{-} / I_{+}\right)^{2}+I_{-} / 2 I_{+}}-I_{-} / I_{+}\right)$

For the calculation model of the composite beam-column substructure in the elastic stage shown in Fig. 5, the vertical deformation $v$ at the failure column and the beam bending moments at the failure column $M_{\mathrm{m}}$ and at the side columns $M_{\mathrm{Ra}}$ and $M_{\mathrm{Rb}}$ were determined as follows:

$$
\begin{aligned}
& v=c_{\mathrm{s}} v_{\mathrm{s}}+c_{\mathrm{f}} v_{\mathrm{f}}=\frac{P L_{1}^{2} L_{2}^{2}}{3 E I_{+} L}\left(\frac{L_{1} L_{2}}{L^{2}} c_{\mathrm{f}}+c_{\mathrm{s}}\right) \\
& M_{\mathrm{m}}=c_{\mathrm{s}} M_{\mathrm{sm}}+c_{\mathrm{f}} M_{\mathrm{fm}}=\frac{P L_{1} L_{2}}{L^{3}}\left(L^{2} c_{\mathrm{s}}+2 L_{1} L_{2} c_{\mathrm{f}}\right) \\
& M_{\mathrm{Ra}}=c_{\mathrm{f}} M_{\mathrm{fa}}=\frac{P L_{1} L_{2}^{2}}{L^{2}} c_{\mathrm{f}} \\
& M_{\mathrm{Rb}}=c_{\mathrm{f}} M_{\mathrm{fb}}=\frac{P L_{1}{ }^{2} L_{2}}{L^{2}} c_{\mathrm{f}}
\end{aligned}
$$

According to Eq. (9), the equation for the bearing capacity at the failure column of the composite beam-column substructure in the elastic stage is written as:

$$
P(1)=\frac{3 E I_{+} L^{3} v}{L_{1}^{2} L_{2}^{2}\left(L_{1} L_{2} c_{\mathrm{f}}+L^{2} c_{\mathrm{s}}\right)}
$$

It is easy to observe that the rotational constraint coefficient $c_{\mathrm{f}}$ determines where the plastic hinge appears earliest in the failure column and side column. In the case where $L_{1}>L_{2}$ and $M_{\mathrm{Ra}}<M_{\mathrm{Rb}}$, the plastic hinge might appear on the right side of the failure column or at end $\mathrm{b}$ of the composite beam.

If the right side of the failure column yields earlier than end $b$ of the composite beam, then:

$$
P_{\text {fim }}=\frac{M_{\mathrm{p}+} L^{3}}{L_{1} L_{2}\left(L^{2} c_{\mathrm{s}}+2 L_{1} L_{2} c_{\mathrm{f}}\right)}
$$

However, if end $\mathrm{b}$ of the composite beam yields earlier than the right side of the failure column, then:

$$
P_{\mathrm{fb}}=\frac{M_{\mathrm{p}-} L^{2}}{L_{1}^{2} L_{2} c_{\mathrm{f}}}
$$

Note that:

1) When,

$$
P_{\mathrm{fim}} \leq P_{\mathrm{fb}} \Rightarrow c_{\mathrm{f}} \leq \frac{M_{\mathrm{p}-} L^{2}}{M_{\mathrm{p}+} L L_{1}+M_{\mathrm{p}-} L^{2}-2 M_{\mathrm{p}-} L_{1} L_{2}},
$$

the right side of the failure column yields earlier than end $b$ of the composite beam, and

$$
P_{\mathrm{A}}=P_{\mathrm{fm}}, \quad v_{\mathrm{A}}=\frac{P_{\mathrm{A}} L_{1}^{2} L_{2}^{2}}{3 E I_{+} L}\left(\frac{L_{1} L_{2}}{L^{2}} c_{\mathrm{f}}+c_{\mathrm{s}}\right)
$$

2) When,

$$
P_{\mathrm{fim}}>P_{\mathrm{fb}} \Rightarrow c_{\mathrm{f}}>\frac{M_{\mathrm{p}-} L^{2}}{M_{\mathrm{p}+} L L_{1}+M_{\mathrm{p}-} L^{2}-2 M_{\mathrm{p}-} L_{1} L_{2}},
$$

end $\mathrm{b}$ of the composite beam yields earlier than the right side of the failure column, and

$$
P_{\mathrm{A}}=P_{\mathrm{fb}}, \quad v_{\mathrm{A}}=\frac{P_{\mathrm{A}} L_{1}^{2} L_{2}^{2}}{3 E I_{+} L}\left(\frac{L_{1} L_{2}}{L^{2}} c_{\mathrm{f}}+c_{\mathrm{S}}\right)
$$

Here, $P_{\mathrm{A}}$ and $v_{\mathrm{A}}$ are the values corresponding to Point $\mathrm{A}$ on the load-deformation curve of the failure column (Fig. 3).

\subsection{Elastic-plastic stage}

The elastic-plastic stage occurs between the elastic and plastic stages. To simplify analysis, a linear transition between the stages was adopted, so the equation for the bearing capacity at the failure column of the composite beam-column frame is as follows: 


$$
P(2)=\frac{P_{\mathrm{B}}-P_{\mathrm{A}}}{v_{\mathrm{B}}-v_{\mathrm{A}}}\left(v-v_{\mathrm{A}}\right)+P_{\mathrm{A}}
$$

where $P_{\mathrm{B}}$ and $v_{\mathrm{B}}$ are the values corresponding to Point B in Fig. 3. The end of the elastic-plastic stage is marked by the development of plastic hinges on both sides of the failure column and at beam ends $a$ and $b$. The calculation model at this time is shown in Fig. 6, where $\theta_{1}$ and $\theta_{2}$ are the beam end angles opposite the failure column, ignoring the bending deformation of the composite beam. According to the principle of virtual work (excluding the axial force and axial deformation in the composite beam), and referring to the calculation method of the deflection of a simply supported composite beam[16], the corresponding bearing capacity and deformation can be obtained as follows:

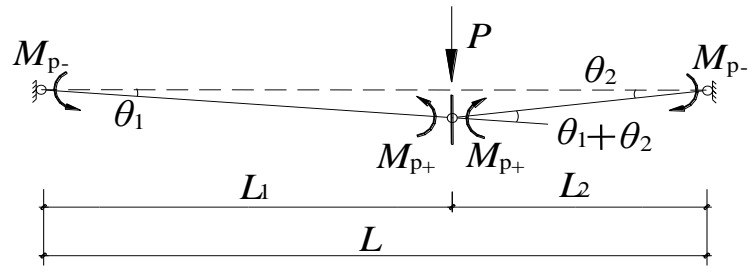

Fig.6. Analysis model in the plastic stage

$\Sigma M \times \theta=P \Delta \Rightarrow P_{\mathrm{B}}=\left(M_{\mathrm{p}^{-}}+M_{\mathrm{p}^{+}}\right) \frac{L}{L_{1} L_{2}}$

$v_{\mathrm{B}}=\frac{P L_{2}\left(L^{2}-L_{2}{ }^{2}\right)^{\frac{3}{2}}}{9 \sqrt{3} E I_{+} L}$

By substituting these expressions for $P_{\mathrm{B}}$ and $v_{\mathrm{B}}$ into Eq. (18), the correlation between bearing capacity and deformation at the failure column in the elastic-plastic stage can be obtained.

\subsection{Plastic stage}

In the plastic stage, plastic hinges appear on both sides of the failure column and at beam ends $\mathrm{a}$ and $\mathrm{b}$, and the resistance of the frame no longer increases. In this case, $P(3)=P_{\mathrm{C}}=P_{\mathrm{B}}$ and the axial tension in the composite beam remains small. As the deformation increases, the internal force in the composite beam changes from primarily a bending moment to a combined bending moment and axial force. The catenary mechanism then gradually becomes dominant and the structure enters the transient stage. The final vertical deformation of the plastic stage $v_{\mathrm{C}}$ was analyzed using the conversion process from the plastic hinge mechanism to the catenary mechanism. The detailed derivation process is shown in section 3.4.

\subsection{Transient stage}

In the transient stage, due to the presence of axial force in the composite beam, the axially constrained spring at the beam ends begins to participate in the work. To simplify analysis, we assumed that the axial forces in the left and right span beams are equal $[9,17]$ and that there is no eccentricity. The equivalent axial stiffness $K_{\mathrm{e}}$ of the composite beam can then be given by:

$$
K_{\mathrm{e}}=\frac{1}{1 / K_{\mathrm{ac}}+1 / K_{\mathrm{as}}+1 / K_{\mathrm{R}}}
$$

where $K_{\mathrm{ac}}$ is the axial stiffness of the composite beam; $A_{\mathrm{c}}$ is the sum of the cross-sectional area of the steel beam and the area of the steel bars in the concrete slab; $K_{\mathrm{as}}=48 E I_{\mathrm{c}} / L_{\mathrm{c}}{ }_{\mathrm{c}}$ is the axial stiffness provided by the side column, where $I_{\mathrm{c}}$ is the section moment of inertia of the column; and $K_{\mathrm{R}}$ is the axial restraint stiffness provided by the perimeter members of the beam-column joint.

The calculation model of the composite beam-column frame in the transient stage is shown in Fig. 7. As the deformation increases, the axially constrained spring at the composite beam end is continuously elongated. If the left span is analyzed, the geometric relationship can be approximated as follows:

$L_{1}^{2}=v^{2}+\left(L_{1}-D_{\mathrm{a}}\right)^{2}$

$D_{\mathrm{a}}=v^{2} / 2 L_{1}$

$$
\partial D_{\mathrm{a}}=v \partial v / L_{1}
$$

where $D_{\mathrm{a}}$ is the horizontal deformation of composite beam end a. Similar relationships can be written with $D_{\mathrm{b}}$ :

$$
\begin{aligned}
& D_{\mathrm{b}}=v^{2} / 2 L_{2} \\
& \partial D_{\mathrm{b}}=v \partial v / L_{2}
\end{aligned}
$$

According to the rigid plastic hinge model, the horizontal deformation of the beam end includes the axial spring deformation and plastic hinge deformation.

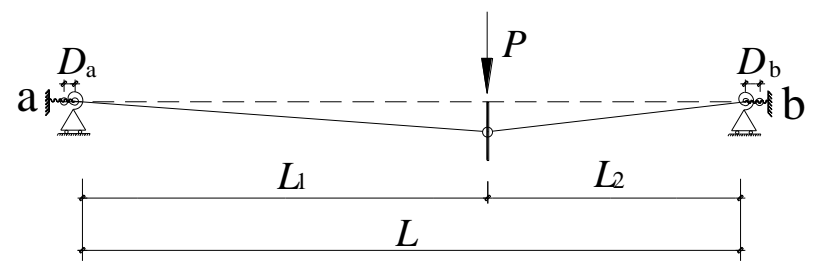

Fig.7. Analysis model in the transient stage

Hence, the total elastic elongation of the equivalent axial spring of the composite beam is as follows:

$D_{\mathrm{e}}=D_{\mathrm{a}}+D_{\mathrm{b}}-D_{\mathrm{pm}+}-D_{\mathrm{pa}-}-D_{\mathrm{pb}-}$

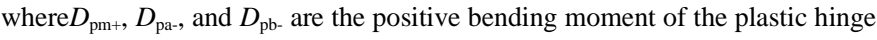
at the failure column of the composite beam, and the negative bending moment of the plastic hinges at the composite beam ends a and $b$, respectively. The axial tension provided by the axial spring is:

$N=K_{\mathrm{e}} D_{\mathrm{e}}$

With the differential of Eq. (28) given by:

$\partial N=K_{\mathrm{e}} \partial D_{\mathrm{e}}$

Substituting Eq. (27) into Eq. (29):

$\partial N=K_{\mathrm{e}}\left(\partial D_{\mathrm{a}}+\partial D_{\mathrm{b}}-\partial D_{\mathrm{pm}+}-\partial D_{\mathrm{pa}_{-}}-\partial D_{\mathrm{pb}-}\right)$

According to the plastic yield flow criterion,

$\partial D_{\mathrm{p}} N_{\mathrm{p}}=\partial \theta_{\mathrm{p}} M_{\mathrm{p}}$

where $N_{\mathrm{p}}$ is the plastic axial force of the composite beam section. $M_{\mathrm{p}} / N_{\mathrm{p}}$ is defined as $r_{\mathrm{p}}$, where positive and negative bending moments in the plastic hinge corresponds to $r_{\mathrm{p}+}$ and $r_{\mathrm{p}-}$, respectively. Ignoring the bending deformation of the beam, for a rigid plastic hinge, the plastic angular increment is approximated by:

$$
\partial \theta_{\mathrm{pa}-}=\partial v / L_{1}, \quad \partial \theta_{\mathrm{pb}-}=\partial v / L_{2}, \quad \partial \theta_{\mathrm{pm}+}=L \partial v / L_{1} L_{2}
$$

Substituting Eq. (31) and (32) into Eq. (30):

$\partial N=K_{\mathrm{e}}\left(\frac{v \partial v}{L_{1}}+\frac{v \partial v}{L_{2}}-\frac{L \partial v}{L_{1} L_{2}} r_{\mathrm{p}+}-\frac{\partial v}{L_{1}} r_{\mathrm{p}-}-\frac{\partial v}{L_{2}} r_{\mathrm{p}-}\right)$

The plastic stage (Phase (3) in Fig. 3) was assumed to have no axial tension, where $v_{\mathrm{C}}$ of the failure column at the end of the plastic stage (the beginning of the transient stage) was determined using Eq. (32) as:

$v_{\mathrm{C}}=r_{\mathrm{p}+}+r_{\mathrm{p}-}$ 
Integrating Eq. (32), the axial force $N$ is obtained as follows:

$N=\frac{K_{\mathrm{e}} L}{2 L_{1} L_{2}}\left(v-r_{\mathrm{p}+}-r_{\mathrm{p}-}\right)^{2}$

The force in the composite beam-column frame under progressive collapse in the transient stage is thus as shown in Fig. 8 (considering the left span for analysis).

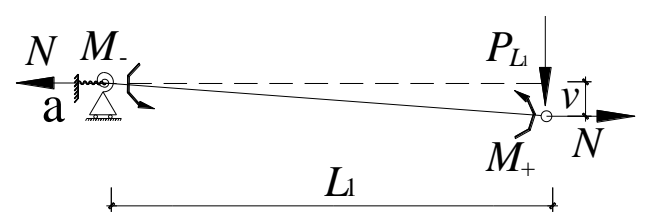

Fig.8. Force diagram of the composite beam in the transient stage

According to the relevant equation for bending moment and axial force (Eq. (1)), combined with the torque balance condition shown in Fig.9:

$M_{-}+M_{+}+N v=P_{L_{1}} L_{1}$

$M_{\mathrm{p}-}+M_{\mathrm{p}+}+N\left[v-\left(r_{\mathrm{p}+}+r_{\mathrm{p}-}\right)\right]=P_{L_{1}} L_{1}$

The equation for bearing capacity of the failure column in the transient stage is thus:

$P(4)=\frac{L}{L_{1} L_{2}}\left(M_{\mathrm{p}-}+M_{\mathrm{p}+}\right)+\frac{K_{\mathrm{e}} L^{2}}{2 L_{1}^{2} L_{2}^{2}}\left(v-r_{\mathrm{p}+}-r_{\mathrm{p}-}\right)^{3}$

At the end of the transient stage, the axial tension causes the composite beam to reach full-section yield (in which the bending moment in the beam is zero and the beam mechanism has ceased to function altogether). Then, the deformation of Point D in Fig. 3 is obtained from Eq. (35) as:

$v_{\mathrm{D}}=r_{\mathrm{p}+}+r_{\mathrm{p}-}+\sqrt{\frac{2 N_{\mathrm{p}} L_{1} L_{2}}{K_{\mathrm{e}} L}}$

By substituting $v_{\mathrm{D}}$ from Eq. (39) into Eq. (38), the corresponding bearing capacity $P_{\mathrm{D}}$ at Point D can be obtained.

\subsection{Catenary stage}

In the catenary stage, the axial force in the composite beam section reaches $N_{\mathrm{p}}$ and then remains unchanged. As the deformation increases, the effect of the catenary mechanism becomes increasingly significant. At this time, the bending moment in the beam is ignored, and the composite beam represents the tensile force of the two-bar system. Therefore, the bearing capacity at the failure column is written as:

$$
P(5)=\frac{L}{L_{1} L_{2}} N_{\mathrm{p}} v
$$

Related studies [18] have shown that when the relative $\mathrm{v}$ of the failure column exceeds one-fifth of the short beam span, frame failure can be considered as the collapse failure criterion of the structure.

\section{Analysis of anti-collapse mechanism}

\subsection{Experimental tests}

Previously, a progressive collapse test of a 1/3-scale composite beam-column frame consisting of four spans connected by rigid joints was conducted [19]. The dimensions and joint details of the specimen are shown in Figs. 9a and 9b.The steel columns and beams were $\mathrm{H} 200 \times 200 \times 8 \times 12(\mathrm{~mm})$ and $\mathrm{H} 200 \times 100 \times 5.5 \times 8(\mathrm{~mm})$ sections, respectively, of Q235B Chinese grade material. The concrete strength grade was $\mathrm{C} 30$, the thickness of the concrete slab was $100 \mathrm{~mm}$, the concrete cube compressive strength was $24.5 \mathrm{MPa}$, and its elastic modulus was $2.65 \times 10^{4} \mathrm{MPa}$. The steel bars in the concrete slab wereHPB235 and were arranged in the slab as shown in Fig. 9c. A summary of the material properties of the steel components are listed in Table 1.

(a) Dimensions of the test specimen

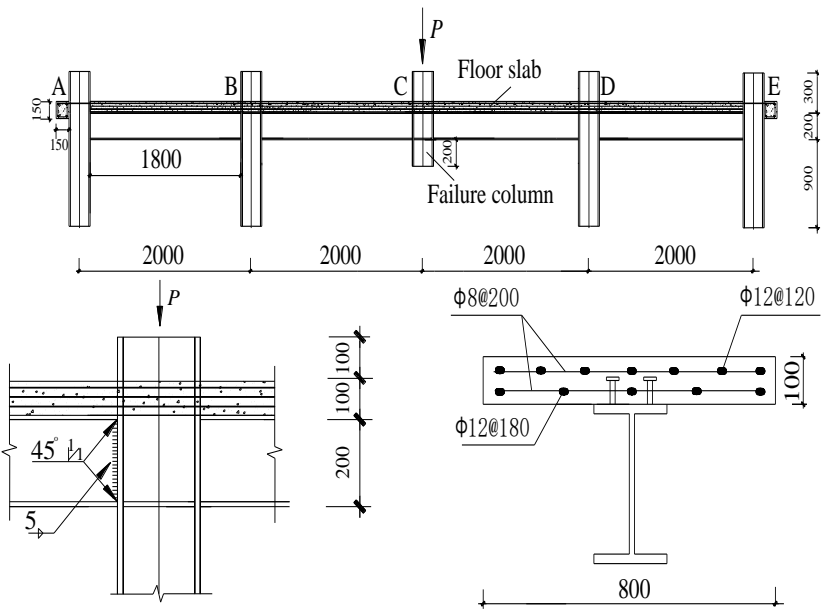

(b) Connection details

(c) Layout of the rebar in the RC slab

Fig. 9. Composite beam-column frame test specimen (dimensions in $\mathrm{mm}$ )

Table 1

Material properties of the steel used in the test specimens

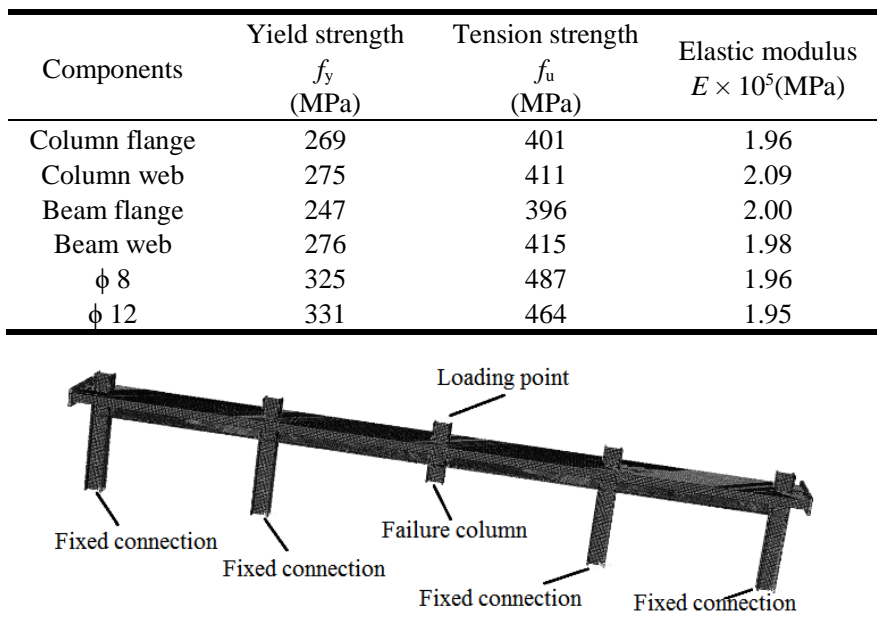

Fig. 10. Numerical analysis model of composite beam-column frame

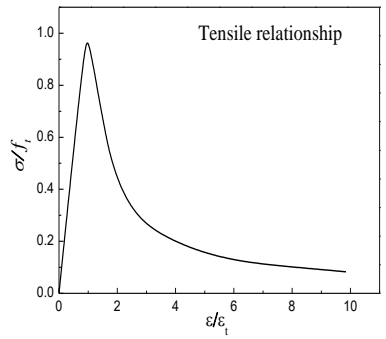

(a) Tensile relationship

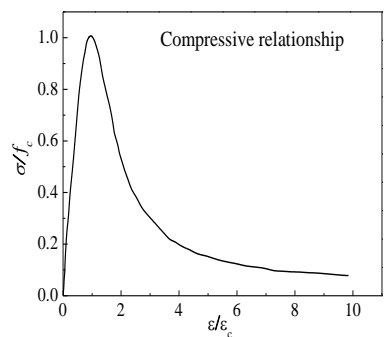

(b) Compressive relationship

\subsection{Numerical simulation}

Fig. 11. Stress-strain relationship of concrete

The numerical analysis model of the composite beam-column frame established in ABAQUS in a previous study [19] was used here, as shown in Fig.10. The beam-column members and the concrete slab were all constructed using C3D8R solid elements, and the steel bars in the concrete slab were constructed using T3D2 truss elements. The steel material was represented by the double-fold line constitutive model; its Poisson's ratio was 0.3 and the material properties shown in Table 1were used as input data. The concrete material was represented by the stress-strain relationship of C30 concrete as recommended in Appendix $\mathrm{C}$ of the Concrete Structure Design Code GB50010-2010 [20], as shown in Fig.11. The modeling method is described in detail in Section 6.2.

\subsection{Numerical simulation and experimental results}

A comparison of the bearing capacity-deformation curves determined using the numerical simulation (FE1) and experiments (Test) at the failure 
column is shown in Fig.12. In general, the results of the numerical simulation agreed well with those of the experiment. However, because the arch action is not fully described in the numerical simulation, the first bearing capacity peak (around point B') was not obvious in the modeled curve. Overall, the numerical analysis model established here simulates the collapse resistance of composite beam-column frames after the failure of the middle column quite well, and can be used for analysis of progressive collapse of similar substructures.

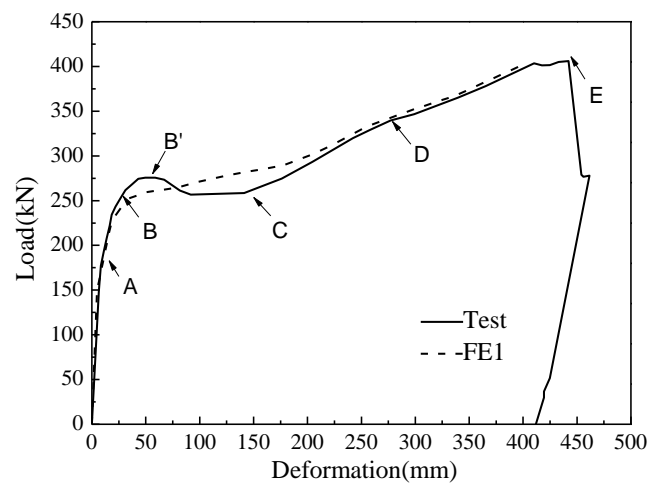

Fig. 12. Comparison between load-deformation curves from the numerical simulation (FE1)and experiments (Test). Points A-E are as defined in Fig. 3, while point B' is the point of peak load.

\subsection{Verification of theoretical equation}

Figure 13 shows a comparison of the load-deformation curves of the test results, numerical simulations, and theoretical equation (SM1). The theoretical curve better matched that of the experimental results in the initial stages compared to the numerical simulation curve, although the stiffness was greatly overestimated by the theoretical equation in the catenary stage compared to the other curves. This was mainly due to the fact that the side span of the frame selected in the physical test cannot provide sufficient axial constraint for the failure span; hence, the horizontal restraint stiffness of the composite beam of the failure span was too small to fully develop the catenary effect.

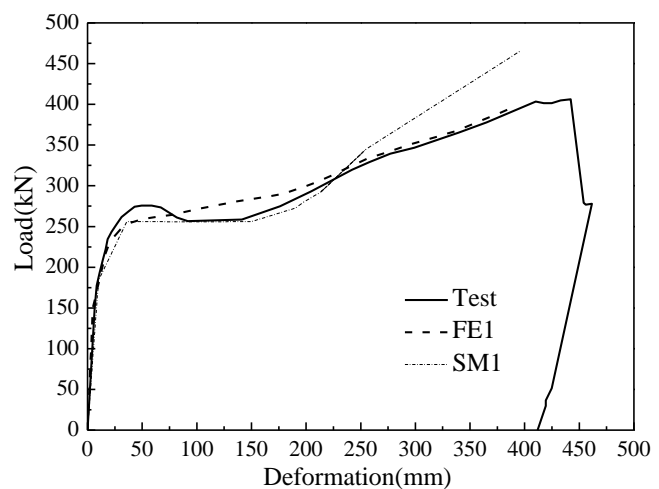

Fig.13.Load-displacement curves produced using the theoretical equation (SM1), numerical simulation (FE1), and experimental results (Test)

We applied an effective axial lateral constraint to both ends of the model (ends A and E shown in Fig.9a), which resulted in curve FE2 from the numerical simulation, as shown in Fig.14.Although the lateral constraint boundary condition has little effect on the initial stage of collapse, when the frame enters the transient stage, the ultimate anti-collapse bearing capacity of the structure significantly increased and its deformation significantly reduced. The FE2 curve matched that of the theoretical equation (SM1) extremely well in the catenary stage; hence, the axial constraint applied at the beam ends provided a more accurate description of the actual catenary mechanism of the structure in the late stage of collapse.

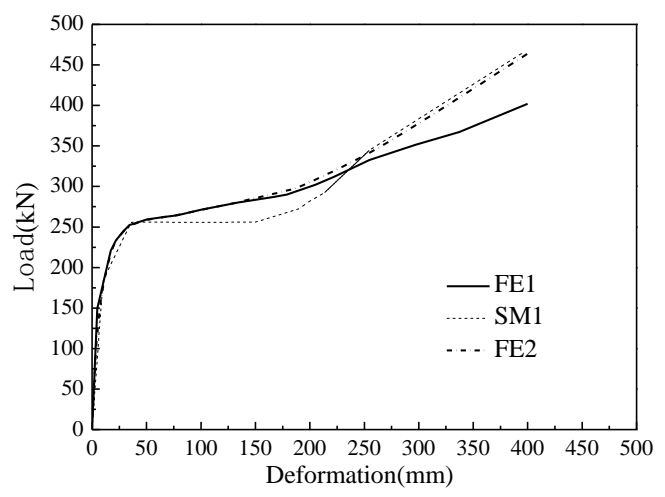

Fig. 14. Comparison of the load-displacement curves using the theoretical equation (SM1) compared to numerical simulations with (FE2) and without (FE1) axial constraints.

\section{Analysis of arch action}

\subsection{Calculation of arch action}

The application of a concentrated load at the failure column causes the beam ends at the side column to be subjected to a negative bending moment. As the applied load increases, the crack developed in the upper tension zone of the composite beam section near the side column will continue to develop, resulting in the neutral axis (bending axis) moving downward. However, the beam end section at the failure column is subjected to a positive bending moment, where the neutral axis is biased toward the concrete slab. Therefore, the curved neutral axis of the cross-section at both ends of the composite beam is not in a horizontal plane, but rather in the form of an arch, which results in a load distribution referred to as the arch action, as shown in Fig.15.Under the arch action of the composite beam shown in Fig.15, the rotating end sections of the composite beams at the failure column form the crown of the arch, and the rotating end sections of the composite beams at the side column form the haunches of the arch, resulting in an arch rib in the oblique direction with a height of $\triangle$.

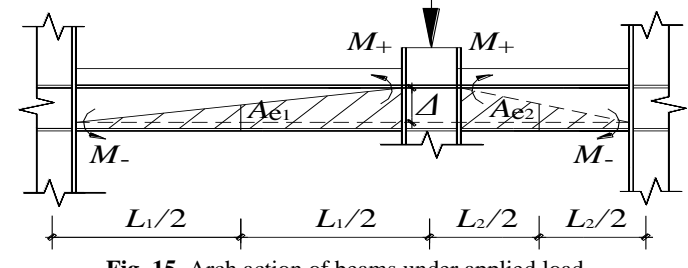

Fig. 15. Arch action of beams under applied load

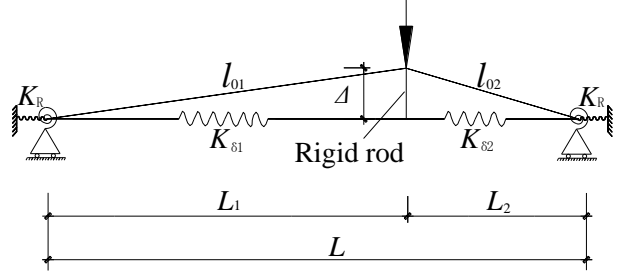

Fig. 16. Arch spring model of a beam under applied load

If the axial constraint of the composite beam is simplified to a spring constraint with stiffness $K_{R}$, the arch spring model shown in Fig.16 is obtained [19]. In this model, in addition to the diagonal arch rib members, the lower flange and a portion of the web are considered as spring-loaded members. The oblique arch rib member and the spring rod member are connected by an incompressible rigid rod member (in which the beam-column joint at the failure column is considered to be a rigid body). Here, $l_{01}$ and $l_{02}$ are defined as the lengths of the ribs, where $l_{01}=\left(L_{1}^{2}+\Delta^{2}\right) 0.5$ and $l_{02}=\left(L_{2}^{2}+\Delta^{2}\right)^{\wedge} 0.5$.

Under the applied vertical load at the failure column, the horizontal deformations of the beam ends at the side columns are $d_{1}$ and $d_{2}$, and the spring deformation elongations are $\delta_{1}$ and $\delta_{2}$, respectively, as shown in Fig. 17. 


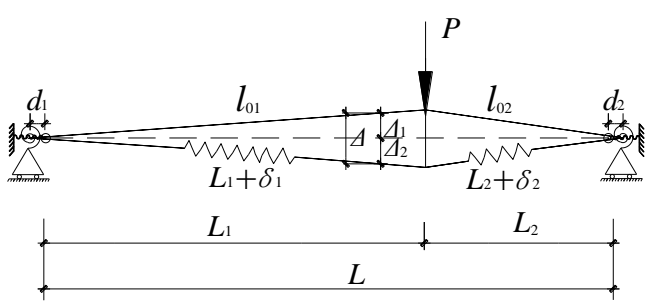

Fig.17. Deformation of the arch spring model

For $\Delta_{2}=v$, then

$\Delta_{1}=\Delta-v$

For the left half of the span:

$d_{1}=\sqrt{l_{01}^{2}-\Delta_{1}^{2}}-L_{1}=\sqrt{l_{01}^{2}-(\Delta-v)^{2}}-L_{1}$

$\delta_{1}=\sqrt{v^{2}+l_{01}{ }^{2}-\Delta_{1}{ }^{2}}-L_{1}=\sqrt{v^{2}+l_{01}{ }^{2}-(\Delta-v)^{2}}-L_{1}$

For the right half of the span:

$d_{2}=\sqrt{l_{02}^{2}-\Delta_{1}^{2}}-L_{2}=\sqrt{l_{02}^{2}-(\Delta-v)^{2}}-L_{2}$

$\delta_{2}=\sqrt{v^{2}+l_{02}{ }^{2}-\Delta_{1}^{2}}-L_{2}=\sqrt{v^{2}+l_{02}{ }^{2}-(\Delta-v)^{2}}-L_{2}$

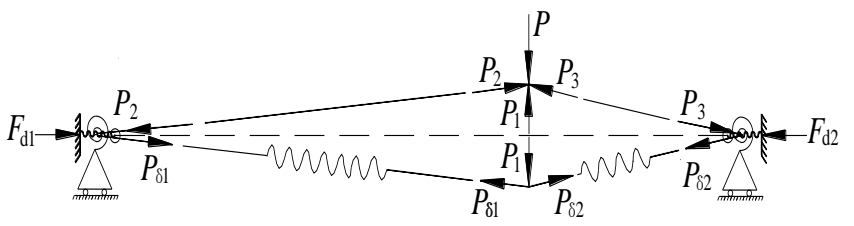

Fig.18. Force diagram of the composite beams under arch action

The forces in the composite beams under the conditions of arch action are shown in Fig. 18. According to the equilibrium condition, this force can be obtained as follows:

$P_{1}=P_{\delta 1} \frac{v}{L_{1}+\delta_{1}}+P_{\delta 2} \frac{v}{L_{2}+\delta_{2}}$

$P_{2} \frac{L_{1}}{l_{01}}=K_{\mathrm{d}} d_{1}+P_{\delta 1} \frac{L_{1}}{L_{1}+\delta_{1}}$

$P_{3} \frac{L_{2}}{l_{02}}=K_{\mathrm{d}} d_{2}+P_{\delta 2} \frac{L_{2}}{L_{2}+\delta_{2}}$

(48) $P_{\delta 1}=K_{\delta 1} \times \delta_{1}, \quad P_{\delta 2}=K_{\delta 2} \times \delta_{2}$

$P=P_{1}+P_{2} \frac{\Delta-v}{l_{01}}+P_{3} \frac{\Delta-v}{l_{02}}$

where $K_{\delta}$ is the axial spring stiffness of the rod, calculated by:

$K_{\delta 1}=\frac{E A_{\mathrm{e} 1}}{L_{1}}, \quad K_{\delta 2}=\frac{E A_{\mathrm{e} 2}}{L_{2}}$

$A_{\mathrm{e} 1}$ and $A_{\mathrm{e} 2}$ are the areas of the steel beams on each side of the failure column below the mid-span oblique rib line prior to column failure[19], as shown in Fig. 15.Substituting Eqs. (46)-(49) into Eq. (50) yields:

$$
\begin{aligned}
& P_{\Delta}=\left(\frac{K_{\delta 1} \delta_{1}}{L_{1}+\delta_{1}}+\frac{K_{\delta 2} \delta_{2}}{L_{2}+\delta_{2}}\right) v+(\Delta-v) \quad(v \leq \Delta) \\
& \times\left[\frac{K_{\mathrm{d}}\left(L_{2} d_{1}+L_{1} d_{2}\right)}{L_{1} L_{2}}+\frac{K_{\delta 1} \delta_{1}}{L_{1}+\delta_{1}}+\frac{K_{\delta 2} \delta_{2}}{L_{2}+\delta_{2}}\right]
\end{aligned}
$$

When the vertical deformation of the failure column is $v=\Delta$, the extrapolated horizontal displacements of the beam ends will reach their maximum value. As the vertical deformation of the failure column continues to increase, the horizontal displacements of the beam ends begin to decrease (pulling inward). At this point, the arch effect fails, and Eq. (52) is no longer applicable. To simplify analysis, the symmetric curve $v=\Delta$ is used to represent the entire arch action phase. When $\Delta<v \leq 2 \Delta$ :

$$
\begin{aligned}
& P_{\Delta}=\left(\frac{K_{\delta 1} \delta_{1}}{L_{1}+\delta_{1}}+\frac{K_{\delta 2} \delta_{2}}{L_{2}+\delta_{2}}\right)(2 \Delta-v)+(v-\Delta) \\
& \times\left[\frac{K_{d}\left(L_{2} d_{1}+L_{1} d_{2}\right)}{L_{1} L_{2}}+\frac{K_{\delta 1} \delta_{1}}{L_{1}+\delta_{1}}+\frac{K_{\delta 2} \delta_{2}}{L_{2}+\delta_{2}}\right] \\
& (\Delta<v \leq 2 \Delta)
\end{aligned}
$$

It should be noted that arch action mainly occurs during the small deformation stage; therefore, it usually functions in the first three stages of progressive collapse, especially during the initial collapse resistance of the plastic stage. According to the superposition principle combined with the theoretical equations of the different collapse stages, the equations for the bearing capacity of the composite beam-column frame considering arch action were obtained:

$P(v)=\left\{\begin{array}{l}P(1)+P_{\Delta} \\ P(2)+P_{\Delta} \\ P(3)+P_{\Delta} \\ P(4)+P_{\Delta} \\ P(5)+P_{\Delta}\end{array}\right.$

When $v \leq \Delta, P_{\Delta}$ is calculated using Eq. (52); when $\Delta<v \leq 2 \Delta, P_{\Delta}$ is calculated using Eq. (53); and when $v>2 \triangle, P_{\Delta}=0$.

\subsection{Experimental verification of arch action}

A comparison between the theoretical calculation results and experimental curves with and without arch action is shown in Fig.19. The theoretical results considering arch action (SM2) better matched the experimental curve (Test). Therefore, it is necessary to consider the influence of arch action in the analysis of the anti-collapse behavior of a structure in the early stages.

A numerical comparison ofexperimental and theoretical results at key points is shown in Table 2. The theoretical results consideringarch action (SM2) were more similar to the experimental ones (Test) than the results that did not consider arch action(SM1). The deviations in the force and deformation

between the theoretical and experimental results were no more than $4 \%$. It can also be observed that the superposition of the calculated arch action upon each stage met the accuracy requirements of engineering calculations.

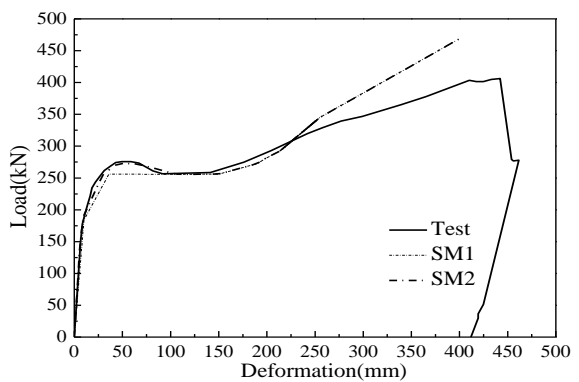

Fig. 19. Comparison of load-displacement curves from theoretical calculations with (SM2) and without (SM1) considering arch action and experimental results (Test) 
It is known from error analysis that arch action can delay the time at which a structure enters the plastic stage, providing conditions for deformation development of the structure. This effect can significantly increase the peak load of the structure so that the initial bearing capacity of the structure is improved, but has almost no effect on the collapse resistance in later stages. In general, arch action has a positive effect on the collapse resistance of the structure.

\section{Numerical analysis}

\subsection{Specimen design}

To verify the reliability of the theoretical equations for the anti-collapse analysis of a composite beam-column frame with unequal spans, several specimens with different span ratios were evaluated. The span ratio of the left-to-right beam $\left(L_{1}: L_{2}\right)$ was set to $1: 1,1: 1.5$, and 1:2, where the length of the right span $L_{2}$ was $3000 \mathrm{~mm}, 4500 \mathrm{~mm}$, and $6000 \mathrm{~mm}$, respectively, the length of the left span $L_{1}$ was $3000 \mathrm{~mm}$ (standard span), and the length of column $L_{\mathrm{c}}$ was $3000 \mathrm{~mm}$. The dimensions of the steel column and beam were HW $300 \times 300 \times 10 \times 16(\mathrm{~mm})$ and HW $300 \times 200 \times 8 \times 12(\mathrm{~mm})$, respectively. The concrete strength grade was $\mathrm{C} 30$, the thickness of the concrete slab was 100 $\mathrm{mm}$, and the effective width of the slab was $1200 \mathrm{~mm}$. Longitudinal HPB300 steel bars were arranged on the top and bottom of the concrete slab and attached to the beam end baffles. The upper row of longitudinal steel bars and the distributed steel bars formed a steel mesh, and the reinforcement ratio was calculated to meet the design requirements. The composite floor slab and steel beams were connected by shear studs with a diameter of $19 \mathrm{~mm}$ and a length of $80 \mathrm{~mm}$. The studs were arranged in a double row with a spacing of $210 \mathrm{~mm}$. The dimensions of the concrete slab and slab reinforcement are shown in Fig.20.

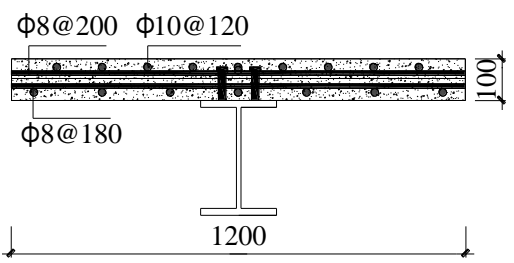

Fig. 20. Arrangement of steel bars in the concrete floor slabs (in $\mathrm{mm}$ )

\subsection{Numerical model}

In the numerical model, the steel was considered an ideal elastic-plastic material with a yield strength of $235 \mathrm{MPa}$, an elastic modulus of $2.06 \times 10^{5}$ $\mathrm{MPa}$ and a Poisson's ratio of 0.3 . The concrete was modeled using the stress-strain relationship of $\mathrm{C} 30$ concrete as recommended in Appendix C of the Concrete Structure Design Code GB50010-2010 [20], as shown in Fig.11. The numerical model used the three-dimensional truss unit T3D2 to simulate the steel bars in the slab, while the eight-node reduced integral solid element C3D8R was used to model the other components.

The welds between the beam and column sections were simulated by a tie constraint. The steel bars and studs in the concrete slab were treated as embedded units. The interfaces between the bolts, webs, and shear tabs were defined as general contacts. Friction was represented by an isotropic Coulomb model, with an assumed friction coefficient of 0.3 , as commonly used for steel-to-steel contact. Considering the influence of large deformations in the calculation, displacement control was used, and the corresponding amplitude was applied in a smooth analysis step. It should be noted that the middle position of the side column must be connected to the fixed connecting plate by establishing an axial connecting unit to simulate the pair of peripheral members, capturing the effects of the frame on the collapse resistance, in which the axial restraint stiffness is $K_{\mathrm{R}}$. The boundary conditions and the mesh division of the numerical model of the composite beam-column substructure are shown in Fig.21.

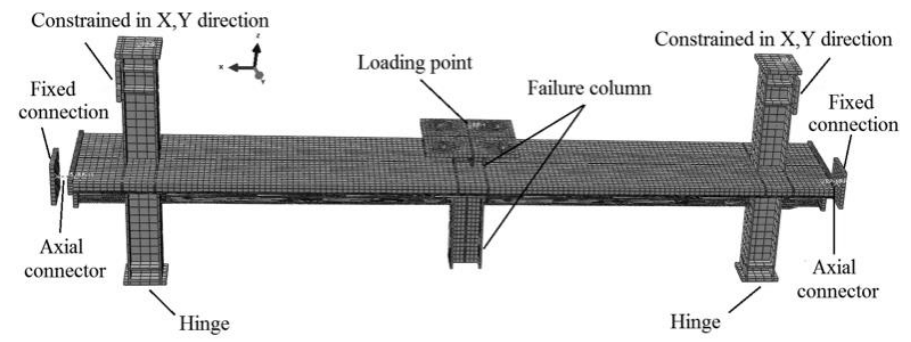

Fig. 21. Numerical model of composite beam-column substructure with unequal spans

\subsection{Validation of the model}

Figure 22 compares the results of the numerical simulations with the theoretical results for the composite beam-column frames with different span ratios. With increasing span ratio, the initial stiffness of the composite beam-column frame decreased, and the catenary effect is postponed, providing conditions for the development of structural deformation. However, the different span ratios had a significant influence on the bearing capacity of the rigid-joint composite beam-column frame. For the same standard span, the geometry with unequal spans had lower resistance to structural collapse. Notably, the composite beam-column frame is subjected to vertical loads. Because of the high stiffness of the short-span beam, it is subjected to a large load as the internal force is redistributed, resulting in the short-span beam yielding earlier than the long-span beam and subsequent destruction of the structure. Finally, the catenary effect of the long-span beam was not fully developed, and the vertical bearing capacity of the structure decreasedwith increasing span ratio. The main reason for the mismatch between the theoretical and numerical results in the transient stage may be due to the theoretical modelnot considering the role of stud tightening, while the $M-N$ relationship (Eq. (1)) used in the transient stage does not fully reflect the bending-tensile performance of the composite joint.

Table 2. Comparison of the key points of the $P-v$ curves of the composite beam-column frame

\begin{tabular}{ccccccccccc}
\hline Key points & \multicolumn{2}{c}{ Test $^{19}$} & \multicolumn{2}{c}{ SM1 } & \multicolumn{2}{c}{ SM2 } & \multicolumn{3}{c}{ Deviation } \\
& $P(\mathrm{kN})$ & $v(\mathrm{~mm})$ & $P_{1}(\mathrm{kN})$ & $v_{1}(\mathrm{~mm})$ & $P_{2}(\mathrm{kN})$ & $v_{2}(\mathrm{~mm})$ & $P / P_{1}$ & $P / P_{2}$ & $v / v_{1}$ & $v / v_{2}$ \\
\hline A & 183 & 10 & 184 & 10 & 184 & 10 & 0.99 & 0.99 & 1.00 & 1.00 \\
B & 252 & 31 & 256 & 36 & 256 & 31 & 0.98 & 0.98 & 0.86 & 1.00 \\
B & 278 & 55 & 256 & - & 274 & 55 & 1.09 & 1.01 & - & 1.00 \\
C & 252 & 157 & 256 & 163 & 256 & 163 & 0.98 & 0.98 & 0.96 & 0.96 \\
D & 338 & 274 & 345 & 268 & 345 & 268 & 0.98 & 0.98 & 1.02 & 1.02 \\
\hline
\end{tabular}




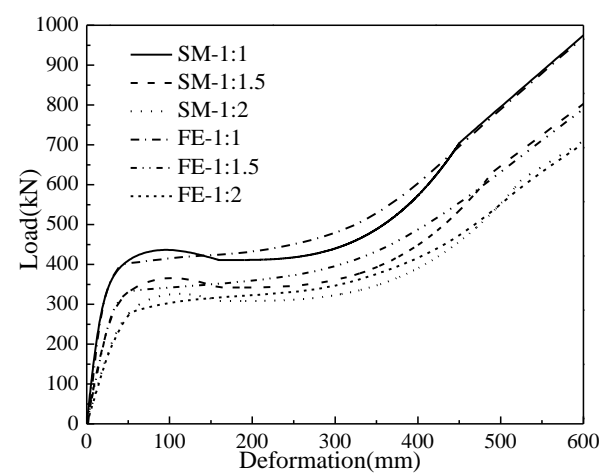

Fig. 22. Load-deformation curves from theoretical calculations (SM) andthe numerical model (FE) for different span ratios

In general, the theoretical and numerical results for structures with different span ratios agreed well, indicating that the theoretical equations provide a high degree of accuracy and meet engineering design requirements. Therefore, the proposed equations can be confidently used as the basis for the evaluation of the anti-collapse resistance of steel-frame structures. It should be pointed out that this work mainly considers the collapse resistance of steel frames connected by rigid joints. When evaluating the more popular semi-rigid joints, due to the diversity of forms, there will be a significant difference in the initial rotational stiffness and the resistance mechanisms of the composite joints under positive and negative bending moments, which will have a large impact on the overall force distribution within the structure. Therefore, the determination and verification of an accurate and reliable evaluation method for the collapse resistance of steel frames connected by semi-rigid joints requires further analysis of systematic test data.

\section{Conclusion}

An anti-collapse calculation model supported by both axial and rotational spring constraints was proposed to investigate a composite beam-column frame with unequal spans.According to the different stress states, the progressive collapse of the structure was divided into five resistance stages and the anti-collapse mechanism was analyzed. The load-deformation curves of the composite beam-column frame at different stages under unequal spans wereanalyzed in detail, and the influence of arch action was fully considered. The entire progressive collapse process was analyzed, indicating that the stress state changed from predominantly bending, to mixed bending-tensile, and finally to a tensile-dominated mechanism resisting the external load. The major conclusions of this study are as follows:

1) The arch action and catenary effect were generated under axial and rotational constraints at the beam ends of the composite beam-column frame. This arch action effectively increased the peak load of the structure in the plastic stage.

2) The theoretical relationship considering arch action described the corresponding experimental results well, indicating that this equation has a high degree of credibility.

3) The numerical analysis and theoretical calculations of the structural behavior with unequal spans showed that with increasing the left-to-right spanratio, the initial stiffness and ultimate bearing capacity of the composite beam-column frame decreased. Hence, unequal spans are not conducive to the development of arch action. Therefore, a structure with equal spans is preferable for improving anti-collapse bearing capacity.

4) The versatility of the theoretical equations derived here was verified by numerical examples with various unequal spans, where the theoretical equations satisfied the accuracy requirements of engineering calculations.

\section{Acknowledgments}

This work was supported by the National Natural Science Foundation of China (Grant No. 51678476). Any opinions, findings, conclusions, and recommendations expressed in this paper are those of the authors and do not necessarily reflect the views of the sponsors.

\section{References}

[1] Demonceau JF, Jaspart JP. Experimental and analytical investigations on the response of structural building frames further to a column loss. Proceedings of the 2009 Structures Congress, 2009: 1801-1810.
[2] Izzuddin BA, Vlassis AG, Nethercot DA. Progressive collapse of multi-storey buildings due to sudden column loss-Part I: Simplified assessment framework. Eng. Struct., 30(5), 1308-1318, 2008.

[3] Izzuddin BA. A simplified model for axially restrained beams subject to extreme loading. Int. J. Steel Struct., 5(5), 421-429, 2005

[4] Vlassis AG., Izzuddin BA., Nethercot DA., Progressive collapse of multi-storey building due to sudden column loss-Part II: application[J]. Eng. Struct., 30(5), 1424-1438, 2008.

[5] Arash N, Fereidoon I. Progressive collapse analysis of steel frames: Simplified procedure and explicit expression for dynamic increase factor. Int. J. Steel Struct., 12(4), 537-549, 2012.

[6] Vlassis AG, Izzuddin BA, Elghazouli AY, et al. Progressive collapse of multi-storey buildings due to sudden column loss-Part II: Application. Eng. Struct., 30(5), 1424-1438, 2008.

[7] Kaiqiang W, Guoqiang L, Taochun Y. A study of re-strained steel beams with catenary action under distributed load-Part I: Theoretical model. China Civil Eng. J., 43(1), 1-7, 2010.

[8] Guoqiang L, Kaiqiang W, Taochun Y. A study of re-strained steel beams with catenary action under distributed load-Part II: Numerical verification. China Civil Eng. J., 43(1), $8-12,2010$.

[9] Weihui Z, Bao M, Jiping H. Analysis of anti-collapse of steel frame beam-column substructure with asymmetric spans. Eng. Mech., 34(5), 125-131, 2017.

[10] GSA 2003. Progressive collapse analysis and design guidelines for new federal office buildings and major modernization projects. Washington, DC: United States General Services Administration, 2003.

[11] Yin YZ, Wang YC. Analysis of catenary action in steel beams using a simplified han calculation method, Part 1: Theory and validation for uniform temperature distribution. J. Constr. Steel Res., 61(2), 183-211, 2005.

[12] Yang B, Tan KH, Xiong G, et al. Experimental study about composite frames under an internal column-removal scenario. J. Constr. Steel Res., 121, 341-351, 2016.

[13] Gao S, Guo LH. Capacity of semi-rigid composite joints in accommodating column loss. J. Constr. Steel Res., 139(139), 288-301, 2017.

[14] Hongtie Z, Sumei Z. Composite structure design principle. Higher Education Press, 2005.

[15] Sucuoglu H, Çitipoglu E, Altin S. Resistance mechanisms in RC building frame subject to column failure. J. Struct. Eng., 120(3), 765-782, 1994.

[16] Xuezhong W, Yazhen S. A simple method for calculating the maximum deflection of simply-supported beams. Mech. Eng., 35(4), 63-64, 2013.

[17] Ying W, Xianglin G, Feng L. Vertical bearing capacity of RC two-bay beams considering compressive arch action. J. Build. Struct., 34(4), 32-42, 2013.

[18] DOD (Department of Defense). Design of Buildings to Resist Progressive Collapse, Unified Facilities Criteria, UFC 4-023-03, USA, 2013.

[19] Guo L, Gao S, Fu F, et al. Experimental study and numerical analysis of progressive collapse resistance of composite frames. J. Constr. Steel Res., 89(5), 236-251, 2013.

[20] GB50010-2010. Code for design of concrete structures. Beijing, China: Architecture \& Building Press, 2010 